\title{
USING SOFT SYSTEMS METHODOLOGY TO ADDRESS SUPPLY CHAIN MANAGEMENT PROBLEMS
}

\author{
Gulender Gencoglu, Graeme Altmann, Ross Smith and David Mackay \\ School of Management Information Systems \\ Faculty of Business and Law \\ Deakin University, Geelong, Victoria, Australia 3217
}

\begin{abstract}
This paper reports an investigation of if, and how, Soft Systems Methodology (SSM) might.be used to facilitate better management of industry supply chains. In two workshops involving supply chain managers from the Textile Clothing and Footwear (TCF) industry and industry facilitators, ways in which SSM techniques might supplement existing Supply Chain Management (SCM) workshop approaches have been explored. Specifically, the placement of SSM techniques within a workshop setting, reactions to the techniques, perceived reasons for using SSM, together with strengths and difficulties encountered, have been examined.
\end{abstract}

Keywords: Soft Systems Methodology (SSM), Supply Chain Management (SCM)

\section{INTRODUCTION}

In the world of eCommerce, Supply Chain Management (SCM) is now mission critical; get it right and a business prospers, get it wrong and it can threaten the very survival of the organisation. SCM involves both optimisation of the delivery of goods and services, and optimisation of information flows. To the customer, optimisation means that the supplier knows what the customer needs and understands the timing of the delivery of goods and/or services. To the supplier, optimisation means that the right goods and/or services are available in the right quantities at the right time, when the customer needs them, without requiring the supplier to carry excess inventory or maintain excessive production capacity.

Interest in SCM has grown steadily since the 1980's, as firms have come to recognise the benefits to be gained from collaborative relationships within and beyond their own organisations. It has been realised that it is not possible for companies to effectively compete in a climate of isolation from their suppliers and other key stakeholders; cooperation brings success for all (Lummus and Vokurka 1999).

The role of technology as an enabler of SCM has facilitated the initial development of relationships between organisations, however technology alone is not sufficient. Businesses are volatile and their operation is dependent upon a chain of cooperating people. Researchers are really now only in the early stages of understanding and modeling the social, cultural and political dimensions of the supply chain, and in particular, understanding how the people focused challenges of managing the supply chain might best be addressed. It remains an open question how supply chain managers might accommodate various stakeholder perspectives of supply chain problems, the cultural, social and political forces at play, the diversity of individual skill and knowledge bases, and diverse individual value systems.

In this paper we report an investigation of if, and how, an existing systems-based problem solving approach, Soft Systems Methodology (SSM), might be used to facilitate better management of industry supply chains. In two workshops involving supply chain managers from the Textile Clothing and Footwear (TCF) industry and industry facilitators, ways in which SSM techniques might supplement existing Supply Chain Management (SCM) workshop approaches have been explored. Specifically, the placement of SSM techniques within a workshop setting, reactions to the techniques, perceived reasons for using SSM, together with strengths and difficulties encountered, have been examined.

Initially in this paper, the scene is set with a brief review of some areas of SCM concern, and recent trends. SSM is then briefly introduced, and the objective of the present research program is established. The research approach is then outlined, including a brief background to the workshop participants and their situation. Some of the key results are then outlined, including insights into the way in which SSM might be integrated with an existing SCM workshop technique used for some years now by the Quick Response (QR) Group within Business Victoria. Some of the perceived strengths of the use of select SSM techniques in this context are reported. Finally, some possible future paths for this research are discussed.

\section{SUPPLY CHAIN MANAGEMENT-AREAS OF CONCERN AND TRENDS}

Areas of current SCM concern have been highlighted by Hakanson (1999), and include:

- Improving customer service - having the right product at the right place at the right time to reduce the number of people purchasing elsewhere; 
- Saving money and reducing costs; and

- Achieving better cash utilisation - the time it takes to be paid for products delivered.

According to $\mathrm{Li}(2000)$, recent trends in supply chain management are now pushing companies to more diverse products, shorter product life cycles, increased competition and ever-increasing globalisation. These trends challenge companies seeking to achieve supply chain efficiencies. $\mathrm{Li}$ argues that in order to address such challenges stakeholders in the supply chain must convene regularly to discuss matters of mutual concern.

One might observe that the above concerns and trends are but symptoms of a fundamental SCM principle. Forger (2000) has suggested that what makes one supply chain better than another is collaboration. Collaboration allows companies to predict supply chain events, as well as permitting suppliers and customers to plan around potential glitches while maximizing their return on supply chain opportunities. Further, the impact of collaboration is not limited to improvements in the inter-organisational chain, but can have profound effects within the four walls of each company making up that chain.

In summary, examination of the SCM literature reveals difficulties with the lack of communication between supply chain partners, cultural inconsistencies, and difficulties with the integration of systems between key stakeholders in the supply chain. In short, if one is to take collaboration seriously, to achieve the full potential of a supply chain, one must be able to analyse the social, cultural, and political dimensions of a SCM situation.

\section{SOFT SYSTEMS METHODOLOGY}

It is beyond the scope of the present paper to review Soft Systems Methodology (SSM) (see Checkland and Scholes (1990) and papers therein). Suffice to say that SSM has been widely used as a general systems-based problem-solving framework but little has been written on its application to SCM problems, although Rigby et al. (2000) makes oblique reference to some perceived shortcomings of SSM when describing research undertaken in the field of agile supply chains (see also Day (1999)).

Developed in the UK and used around the world, SSM provides a set of procedures and notations for investigating organisational problem situations and taking action to improve those situations. SSM has a welldocumented set of processes, supported by a rich set of techniques for finding out about problems and generating systems-based models that can be used to generate systemically desirable and culturally feasible organisational change.

Even though SSM has not been widely applied to addressing problems in supply chain management, the very nature of SSM appears to make it a suitable vehicle to address the social, cultural, and political issues commonly associated with SCM problems. What is evident from a search of the SCM literature is that SCM problems of a human nature are overwhelmingly more common than problems of a technical nature. In this sense, organisations are social systems, as well as business systems - thus the social construction of problematic situations in organisations are complex to understand and manage.

\section{RESEARCH OBJECTIVES}

Reflecting the above observations based upon the extant literature, the aim of this study is to address the research question:

Can SSM be used to complement an existing workshop-based approach for thinking about supply chain management problems by conceptualizing and modeling the key activities of suppliers, retailers and other stakeholders?

As such, can SSM techniques such as rich pictures, CATWOE analysis, root definitions and conceptual models be used to reveal issues that were previously unrecognized by those involved in the management of supply chains?

\section{RESEARCH APPROACH}

Given the exploratory nature of the present research, a case study approach has been used to address the research question. Yin (1985, cited by Rubin and Babbie (1997)) defines a case study as an empirical inquiry that: 'Investigates a contemporary phenomenon within its real-life context; when the boundaries between phenomenon and context are not clearly evident; and in which multiple sources of evidence are used'.

Participants in the present case study were a senior supply chain manager, a production planner, a SCM facilitator and two SSM facilitators. Two half-day workshops were used to collect the data. The SCM facilitator was from Business Victoria, a Victorian Government initiative for improving supply chain management processes within the Textile Clothing and Footwear industry (TCF) industry. The facilitator had extensive experience in running SCM workshops but had no knowledge of SSM. The senior supply chain manager and the 
production planner were from a large Australian company in the TCF industry, specifically a producer of socks and hosiery.

As a producer of socks and hosiery, the organisation manufactures locally as well as importing products that can no longer be cost effectively produced within Australia. The company purchases yarn from local producers and imports yarns. The company sells to the major retail discount stores such as Woolworths, Coles Myer and Big W. They also concentrate on selling their own brands in smaller boutique stores around Australia and are looking at the prospect of exporting niche products, particularly by using Merino wool because it can be marketed as a unique Australian fiber.

The company had been previously involved in meetings initiated and facilitated by a Victorian government SCM facilitator who had spent a considerable amount of time working with TCF companies, forming cluster groups. Those that made up the cluster groups were typically a major retailer, a TCF manufacturer and one or two suppliers to the manufacturer. The aim of convening the cluster groups was to achieve mutual gain by improving their total effectiveness in servicing each other and the end consumer. The format of these earlier meetings was an approach outlined below (see the next section of this paper). It was against the experience of participants in those previous workshops that select SSM concepts and techniques were introduced in the two half-day workshops conducted as part of the present research.

Data collection from the two SSM-based workshops took the form of:

- Some pre and post workshop semi-structured interviews with some of the workshop participants;

- Drawings and written responses to questions asked in the workshop situation; and

- Audio recordings (each workshop was audio recorded with the permission of participants).

Data from the above collected sources were analysed to:

- Document supply chain management processes currently employed by workshop participants;

- Identify SCM issues and problems;

- Identify initial reactions to the SSM techniques introduced in the sessions; and

- Collect reactions to the experience of using SSM techniques in the workshops.

\section{THE INTEGRATION OF SSM WITH EXISTING SCM WORKSHOP APPROACHES}

As indicated above, the workshops discussed in this paper built on previous workshops that had been run over several years by the Quick Response (QR) Group within Business Victoria. This QR program has been documented by Perry et al. (2000) and is summarised on the left-hand side of Figure 1. Specifically, in these workshops senior managers meet regularly in newly formed cluster groups consisting of one or two representatives of major retailers, manufacturers and suppliers. The processes involved in the $\mathrm{QR}$ workshops can be summarised, as shown on the left-hand side of Figure 1, as involving four key features:

1. The generation and circulation of company SCM 'wish lists' within each cluster group;

2. Discussion of the wish lists and the development of group and company action plans;

3. The injection into each group of a consultant selected by the various companies to provide assistance with in-house Quick Response implementation activities; and

4. Follow-up strategic and tactical planning amongst each cluster group.

Results from these QR workshops (Perry et al. 2000) reveal that improved communication and information flow result, as well as improved performance within the supply chains involved.

Prior to the workshops discussed in this paper the present authors speculated on points at which SSM techniques might be injected into the QR workshop process model of Perry et al. (2000). The initial view that was formed is represented by the additional Steps $6 \mathrm{a}, \mathrm{b}$ and $7 \mathrm{a}, \mathrm{b}$ shown on the right of Figure 1 . Specifically, it was felt that the SSM technique of Rich Picture Building and reflection upon those Rich Pictures might facilitate the preparation of the SCM 'wish list' (ie. Steps 6a,b). Further it was felt that the use of CATWOE analysis, SSM Root Definitions and Conceptual Modeling of each node in the supply chain (ie. a "bottom up" development of conceptual models of each node in the supply chain) might provide a useful means of facilitating the identification and specification of in-house improvements (ie. Steps $7 \mathrm{a}, \mathrm{b}$ ).

This possible use of SSM in conjunction with the established QR workshop process model described by Perry et al. (2000) was introduced to workshop participants, and reactions were collected. Results and findings from these workshops follow. 


\section{RESULTS}

\section{The placement of SSM Techniques within the Workshop}

Before looking at the reactions of participants to the individual SSM techniques, it is worth reporting the reactions of those participants to the suggested placement of those techniques within the workshop process. In summary, significant doubt emerged from the participants concerning the suggested placement outlined in Figure 1. Instead, a preferred sequencing, outlined in Figure 2, emerged.
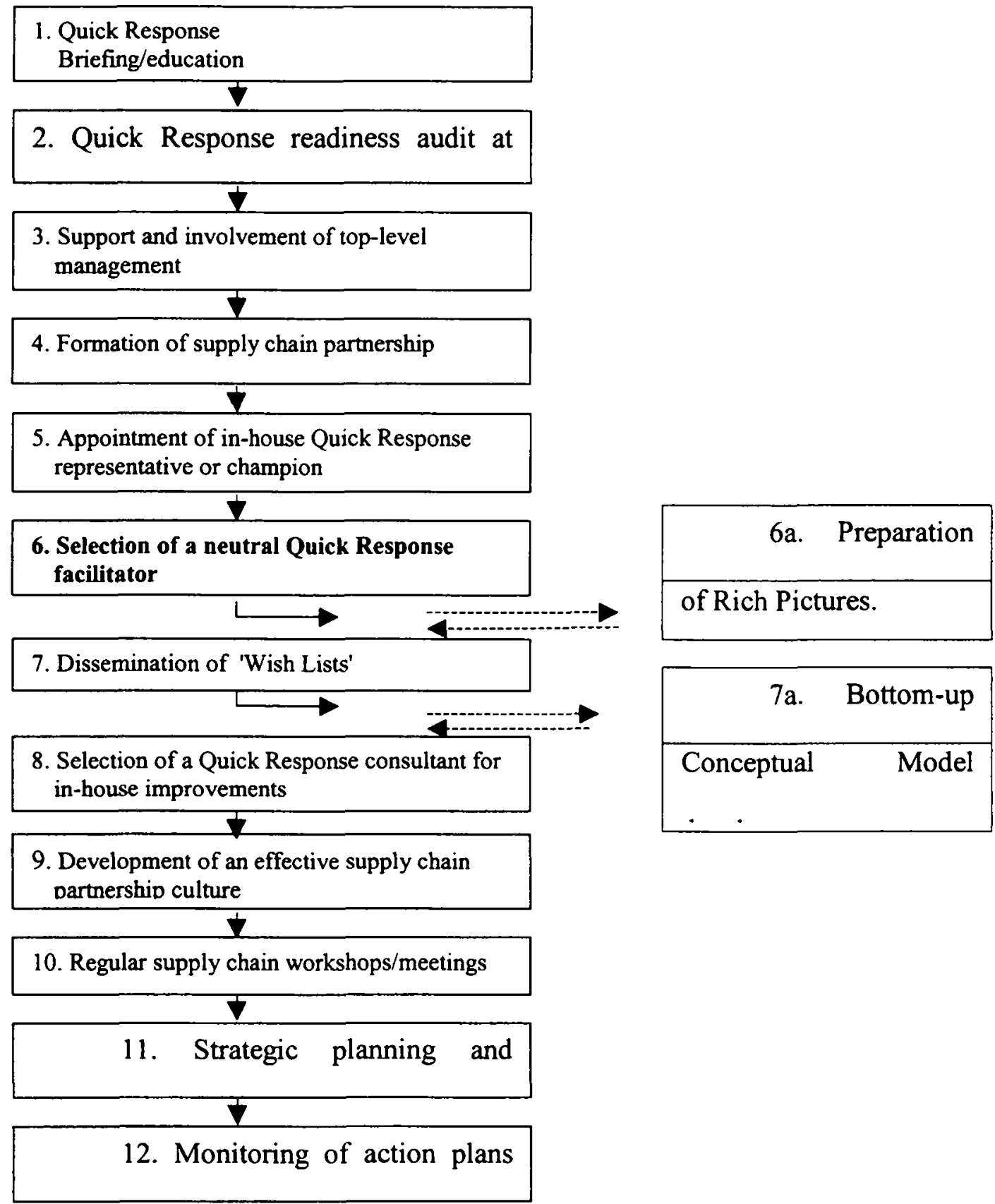

Figure 1: The QR Workshop process model of Perry et al. (2000) (left side), with additional possible points for the inclusion of SSM techniques (right side) 


\section{Quick Response}

Briefing/education

2. Quick Response readiness audit at

3. Support and involvement of top-level
management

4. Formation of supply chain partnership

\begin{tabular}{|l|}
\hline $\begin{array}{l}\text { 5. Appointment of in-house Quick Response } \\
\text { representative or champion }\end{array}$ \\
\hline
\end{tabular}

\begin{tabular}{|l|}
\hline $\begin{array}{l}\text { 6. Selection of a neutral Quick Response } \\
\text { facilitator }\end{array}$ \\
\hline 7. Dissemination of 'Wish Lists' \\
\hline
\end{tabular}

8. Selection of a Quick Response consultant for in-house improvements

\begin{tabular}{|c|c|}
\hline \begin{tabular}{|l|} 
9. Development of an effective supply chain \\
partnership culture
\end{tabular} & $\begin{array}{l}\text { 10a. Preparation of Rich } \\
\text { Pictures }\end{array}$ \\
\hline 10. Regular supply chain workshops/meetings & $\begin{array}{l}\text { 10b. Top - down approach to } \\
\text { Conceptual Model }\end{array}$ \\
\hline 11. Strategic planning and & $\begin{array}{l}\text { 10c. CATWOE serving as a } \\
\text { mission statement. }\end{array}$ \\
\hline
\end{tabular}

\section{Monitoring of action plans}

Figure 2: The QR Workshop process model of Perry et al. (2000) (left side), with the placement of additional SSM techniques preferred by workshop participants (right side)

In summary, the participants argued that:

- The SCM 'wish list' generation step did not require support from SSM Rich Picture building (see further discussion under 'Workshop Techniques' below). Instead, the wish list approach had the advantage of yielding quickly high value insights that build important enthusiasm for the workshops within participants. Use of graphic SSM Rich Picture building and reflection at this very early stage in the life of the workshop group was seen as unnecessarily delaying the realisation of these quick returns. Instead the workshop participants argued that the Rich Picture techniques would be best introduced subsequently, as part of the cycle of regular supply chain workshops/meetings, where it might be used as a technique to identify some of the less readily apparent SCM issues and concerns (Figure 2, Step 10a).

- SSM CATWOE analysis and Conceptual Model Building was seen also as best introduced as part of the subsequent cycle of regular supply chain workshops/meetings (Figure 2, Step 10b). Further, it was believed that the value of the conceptual models came from examining the supply chain from 
a top-down perspective, rather than the bottom-up approach proposed in Figure 1. The CATWOE technique was seen also as a useful means of reviewing/reasoning about the mission of supply chain participants (Figure 2, Step 10c).

\section{Workshop Techniques}

As noted above, the workshop participants strongly supported the retention of the use of wish lists, a central component of the previous $\mathrm{QR}$ workshops. These were seen as a fast way of focussing workshop participants thinking on the main supply chain issues and problems, yielding quick returns to the participants. The wish lists typically contain requests for improved working relationships between partners, improved response to customer orders and reduced pipeline waste and delay. In a sense, the wish lists were simply lists of things participants would ideally like to happen in the supply chain in order to improve their own performance and profitability. It was observed that using wish lists seemed to 'break the ice' with participants.

In the course of the workshop, when the SCM facilitator asked the senior supply chain manager to come up with a wish list, as many as 15 'problems' were produced in a manner of minutes. The $Q R$ facilitator stated reasons as to the usefulness of the wish list approach. They were:

- It gives people ownership, therefore it's not just the facilitator coming in and stating that he is going to rework the supply chain;

- It is the day-to-day things that people are anxious to fix;

- The senior supply chain managers know intimately all the details, thus the solutions are usually fairly readily achieved; and

- It leads the people in the workshop to realise that problems can often be solved by a simple alteration to a requirement or a procedure in another cell.

This is not to say that the SSM techniques, when introduced to the workshop participants, were not appreciated. Indeed, the SCM facilitator commented on the fact that the use of SSM substantially added to the wish list approach:

'After deriving wish lists you end up with informal results. What you want to do then is to add structure, ...now SSM techniques can be used to add that structure.'

What did emerge was that it was felt that the SSM techniques were better introduced after the quick gains achieved by using the wish list approach had been realised. In this regard it is worth noting that the participants observed that it was not a matter of whether it would be useful to apply SSM to SCM, - rather, where and how SSM could be applied.

The collected observations of participants on their exposure to the SSM Rich Picture Building, CATWOE and Conceptual Modeling techniques are recorded as reasons for using SSM (Table 1), identified strengths (Table 2) and difficulties raised (Table 3). It is beyond the scope of the present paper to discuss each of these in detail. Suffice to say that they provide support for the use of SSM in this context, and some insight into potential difficulties that may need to be addressed in future SSM-enabled SCM workshop sessions.

\begin{tabular}{l}
\hline Reason \\
\hline Acknowledges different ideas and perspectives \\
Promotes understanding of SCM concepts \\
Prompts questioning, thinking, and critical analysis \\
Encourages formal consideration of political and social environment \\
Provides a disciplined, formal way to proceed in an unstructured situation \\
Iterative nature of the approach
\end{tabular}

Table 1: Reasons cited by participants for using SSM in the SCM context 


\begin{tabular}{l}
\hline Strength \\
\hline Conceptual nature of the approach \\
Adds structure to wish lists \\
Focuses on the purpose of the chain, systems, needs, outputs ... \\
Practical \\
Promotes creativity and builds confidence \\
Provides discipline and a formal structure \\
Systematic nature of the approach \\
Able to deal with unstructured situations \\
Participative and collaborative in nature \\
Prompts thinking \\
Allows for questioning of the current supply chain arrangements \\
Takes account of social, political and cultural issues
\end{tabular}

Table 2: Strengths of SSM in the SCM context cited by participants

\begin{tabular}{|l|}
\hline Difficulty \\
\hline Learning how to begin to draw Rich Pictures \\
Problems in reaching group consensus \\
Learning how to represent human activities using SSM conceptual models \\
\hline
\end{tabular}

Table 3: Difficulties encountered in the use SSM in the SCM context cited by participants

\section{DISCUSSION AND CONCLUSIONS}

Drawing upon the results reported above, four central themes related specifically to the introduction of SSM techniques and associated concepts have emerged from the research to date:

- It appears that SSM allowed participants to achieve a better understanding of supply chain management processes because it introduces techniques that allow them to quickly see the views and perspectives of other stakeholders. Participants easily take to the use of rich pictures to visually show supply chain processes. Rich pictures accommodate different peoples' image of the chain, and therefore eliminate pressures on the manager to come up with verbal descriptions of systems and processes.

- When an approach involving using CATWOE analysis as a tool for the development of root definitions or SCM 'mission statements' was canvassed, participants felt that by incorporating the elements of customers, actors, transformation, worldview, ownership and environment, they could see and reanalyze the cooperative role of the supply chain.

- Participants saw that the value of conceptual models in the SCM context comes from examining the supply chain from a top-down perspective. Rather than beginning with each participant in a supply chain developing their own activity model and capturing their perceptions of the current sequence of events, it was argued that it was better to start at the top-level and develop fresh views in order to overcome the danger of locking oneself into current practices.

- SSM techniques were seen as generally useful in identifying shared and conflicting views. By having the parties come together in a workshop situation they are able to discuss key processes through the use of universal icons and remove those icons that are not appropriate. This allows inhibitors to a smooth functioning supply chain to be identified so that they can be removed.

It should be noted, however, that the experience reported in this paper is limited to two workshop sessions and associated interactions with the workshop participants. It is therefore important that the findings reported be confirmed by the conduct of a future, richer series of such sessions, with participants drawn across all tiers in supply chains, operating in a number of industrial settings. Results to date, however, are promising.

\section{REFERENCES}

Checkland, P. \& Scholes, J. (1990). Soft Systems Methodology in Action, Chichester: John Wiley \& Sons.

Day, M. (1999). Buyer-supplier Integration in the U.K. Tableware Supply Chain. Unpublished $\mathrm{PhD}$ thesis, University of Keele.

Forger, G. (2000). Collaboration-The Supply Chain's Defining Factor? Supply Chain Management Review. 
Hakanson, B. (1999). Supply Chain Management: Where Today's Business Competes, Ascet.

Li, Y. (2000). Supply Chain Update, Grainger Center for Supply Chain Management.

Lummus, R.R. \& Vokurka, R.J. (1999). Defining Supply Chain Management. Industrial Management \& Data Systems.

Perry, M. \& Sohal, A.S. (2000). Quick Response Practices and Technologies in Developing Supply Chains - A Case Study. International Journal of Physical Distribution \& Logistics Management 30(7/8), pp. 627639.

Rigby, C., Day, M., Forrester, P. \& Burnett, J. (2000). Agile Supply: Rethinking Systems Thinking, Systems Practice. International Journal of Agile Management Systems, 2/3, pp.178-186.

Rubin, A. \& Babbie, E. (1997). Research Methods for Social Work, Brooks/Cole Publishing Company, U.S.A. 